\title{
LOS PENALES EN TIEMPO DE PANDEMIA: UNA FORMA DIFERENTE DE SOBREVIVIR AL CORONAVIRUS
}

\section{PRISONS IN PANDEMIC TIME: A DIFFERENT WAY TO SURVIVE CORONAVIRUS}

José Julio Goicochea Elías Leydy Piñarreta Moreno Ana Omaní Flores

Fiorella Valdivia Fajardo

* Doctor en Derecho, docente universitario en Derecho Penal en coautoría con las estudiantes de la Facultad de Derecho pertenecientes al Círculo de estudio de Derecho Penal de la Universidad del Sagrado Corazón UNIFÉ

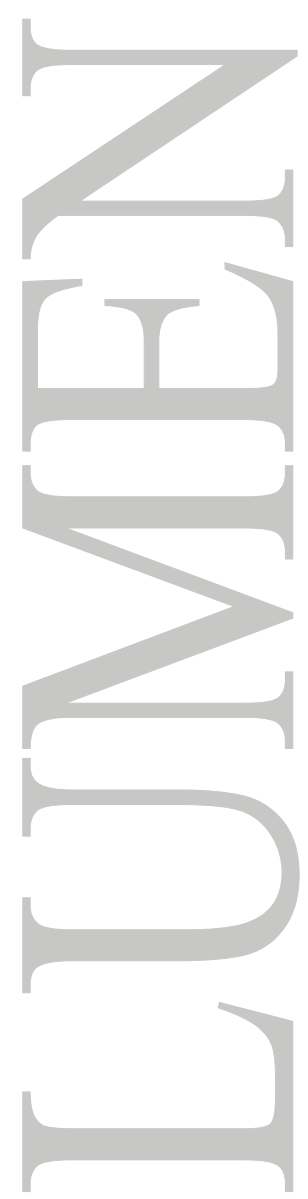




\title{
LOS PENALES EN TIEMPO DE PANDEMIA: UNA FORMA DIFERENTE DE SOBREVIVIR AL CORONAVIRUS
}

\author{
PRISONS IN PANDEMIC TIME: A DIFFERENT WAY TO \\ SURVIVE CORONAVIRUS
}

\author{
José Julio Goicochea Elías \\ Leydy Piñarreta Moreno \\ Ana Romaní Flores \\ Fiorella Valdivia Fajardo
}

\begin{abstract}
RESUMEN:
La situación pandémica que se encuentra atravesando el planeta ha desbordado todas las instalaciones y programas sanitarios. Los centros de internamiento penitenciario no han sido ajenos a esta realidad. A los problemas conocidos de una infraestructura sobrepasada por la población de confinados y la escasa atención médica que trae consigo un alto porcentaje de enfermedades infecto-contagiosas, se le suma este nuevo virus, cuyos efectos totales se desconocen. Es por otra parte preocupante que un alto número de la población penal se encuentre aún con procesos por sentenciar: debido a un abuso excesivo del mecanismo de la prisión preventiva y a la casi nula aplicación por parte de los operadores judiciales de los principios de proporcionalidad y razonabilidad. La cárcel es la excepción. Los jueces la han convertido en regla.
\end{abstract}

\section{PALABRAS CLAVES:}

Hacinamiento Penitenciario, Covid 19, Pandemia, Prisión Preventiva, Gracias Presidenciales

\begin{abstract}
:
The pandemic situation that the planet is going through has overwhelmed all the health facilities and programs. The penitentiary detention centers have not been oblivious to this reality. To the known problems of an infrastructure overwhelmed by the inmate population and to the scarce medical attention that a high percentage of infectious-contagious diseases brings, this new virus is added, the full effects of which are unknown.
\end{abstract}

It is also worrying that a high number of the prison population is still facing sentencing processes: due to excessive abuse of the preventive detention mechanism and the almost null application by the judicial operators of the principles of proportionality and reasonableness. Jail is the exception. The judges have made it the rule.

\section{KEY WORDS:}

Prison Overcrowding, Covid 19, Pandemic, Preventive Prison, Presidential Thanks

\section{INTRODUCCIÓN}

Las situaciones de hacinamiento y de escasa salubridad que presentan los Centros de Internamiento y Readaptación Social (Penales) en el Perú son caóticas. Si a eso le agregamos la mínima atención que ha venido prestando el Estado al problema, aunado a la pandemia que venimos sufriendo, el resultado del coctel obtenido es brutal. Los internos no gozan de una calidad de vida mínima y tienen que rebuscárselas como puedan en medio de precarias condiciones, que generan un ambiente ideal para la propagación de enfermedades infecto-contagiosas, las cuales en muchos casos traen consigo pérdida de vidas humanas y en otros dejan secuelas incurables. Así tenemos que según información que maneja el Instituto Nacional Penitenciario (2020) existen 56,974 reclusos que debido a una sobrepoblación carcelaria no gozan de un espacio adecuado de vivienda. Hemos permitido1 que se edifique un derecho penal para los pobres: porque las cárceles más allá de no 
reunir las condiciones mínimas de salubridad y habitabilidad (se asemejan por sus condiciones a Dachau y Treblinka por decir lo menos), están sobrepobladas por internos de escasos recursos económicos, que si pasan hambre a nadie le preocupa, o si se enferman y mueren descuidados, nadie asume la culpa; en todo caso la responsabilidad era del confinado por delinquir.

\section{CONTEXTO DE LA PROBLEMÁTICA}

La problemática del sistema penitenciario en el Perú no es de la hora actual. Son pocos los gobiernos que han desarrollado políticas públicas que afronten este problema. Consecuentemente, la crisis sanitaria de la pandemia del COVID-19 y la revolución multitudinaria que se ha dado dentro de las cárceles nos han permitido tomar en cuenta tres factores: i) el desastre sanitario que se presenta los penales, ii) la nula atención al tema sanitario por parte del Estado y iii) la necesidad de que se tomen acciones inmediatas. En ese orden de ideas, debemos señalar que se deben implementar políticas serias y que cuenten con el soporte de una base científica desde el Poder Ejecutivo al Poder Judicial para coadyuvar con esta problemática de Estado. Una vez ello, se debe contar con el compromiso total de las partes involucradas al momento de aplicar las normas, porque la historia nos ha enseñado que muchas veces el problema no es la norma, sino más bien el agente que opera sobre la misma.

\section{HACINAMIENTO PENITENCIARIO FRENTE AL CORONAVIRUS}

Siguiendo este razonamiento lógico, podemos señalar que a través de sus gobernantes América Latina en general y el Estado peruano en particular, han demostrado irresponsabilidad y poco compromiso en lo que respecta al diseño de planes de acción frente a los problemas, que a nivel sanitario se han suscitado en las prisiones.

Deacuerdoal Informe de Adjuntía N 006-2018-DPIADHPD (2018), en el primer Informe Defensorial $\mathrm{N}^{\circ} 11$, publicado en 1999 , el total de personas privadas de su libertad alcanzaba a 24,888 personas. Según cifras del Instituto Nacional Penitenciario a agosto del 2018, la población penitenciaria asciende a 89,166 internos e internas mientras que la capacidad de albergue a nivel nacional es solo de 39,156 plazas. Esto significa que existe un nivel de hacinamiento que alcanza el $128 \%$. En el 2011, fecha del último informe defensorial, esta cifra se situaba en el $75 \%$. Ello quiere decir que, en un periodo de 7 años se registra un crecimiento del $53 \%$. En efecto, como se ha podido notar, el hacinamiento es un problema en crecimiento exponencial para la cantidad de cárceles que hay en nuestro país.

Se desprende pues, que el hacinamiento en las cárceles desencadena una serie de fallas en los mecanismos de seguridad y control para los internos. Definitivamente, esta situación, es un llamado de alerta a todos los poderes del Estado, en aras de salvaguardar, ipso facto, los derechos de los reclusos que ya han sido afectados.

En ese orden de ideas, podemos anotar que el Estado peruano ha reconocido a través del Decreto Legislativo № 1325 que el sistema penitenciario se encuentra en crisis. En dicha norma se establece que tanto el Sistema Nacional Penitenciario como el Instituto Nacional Penitenciario se encuentran en estado de emergencia por razones de salud, seguridad, hacinamiento y deficiencia de la infraestructura. El artículo $4^{\circ}$ señala al referirse al tema que nos ocupa lo siguiente:

Que con arreglo a un plan aprobado por la jefatura del Instituto Nacional Penitenciario los servicios de salud, infraestructura, recursos humanos y logísticos se priorizan; que las direcciones regionales, el gobierno de la región y el pliego de salud coordinan con el INPE de qué manera se van a posicionar en los centros de confinamiento los servicios sanitarios y que el INPE será la institución encargada de desarrollar en los penales una infraestructura adecuada con arreglo al precitado plan, para que todos aquellos confinados que sufran de enfermedades transmisibles y/o infecciosas, o que se encuentren pasando por la etapa final de las mismas puedan ser debidamente 
atendidos, así como también de establecer con el fin de garantizar la separación y atención de los internos, todos los protocolos que resulten necesarios.

La pandemia ha encendido el botón rojo de alarma de gobernantes y autoridades sanitarias a nivel global. Estamos viviendo una crisis sanitaria que no distingue raza, sexo, cultura ni billeteras. En ese escenario, el Estado Peruano se ha visto en la necesidad de establecer las medidas necesarias para frenar la propagación del coronavirus.

Para empezar, es importante hacer una delimitación entre las personas procesadas con los sentenciados. En el siguiente gráfico se puede percibir la cantidad de personas sentenciadas y procesadas que componen la población penitenciaria.

\section{Población Penitenciaria}

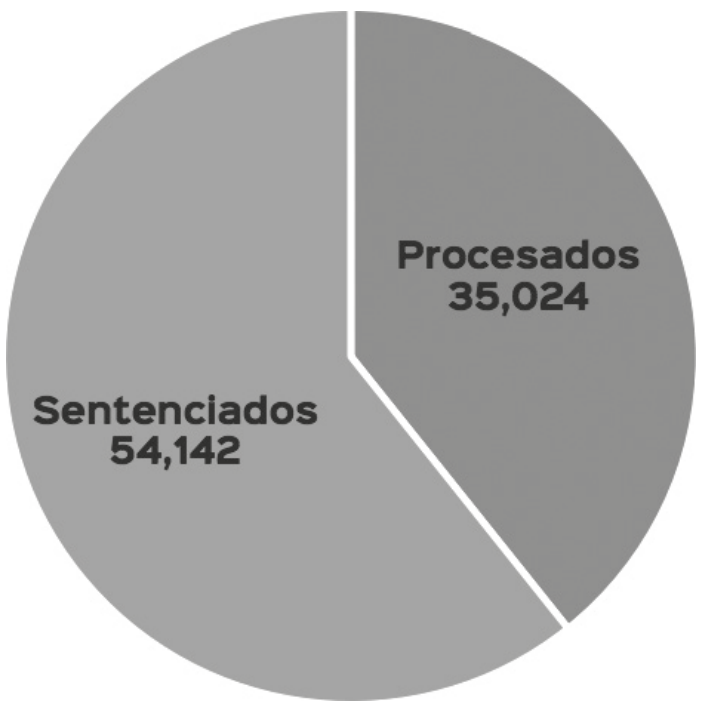

Fuente: Supervisión Nacional a penales (2017)

Elaboración: Defensoría del Pueblo

Por otra parte, el 15 de marzo del presente año, se publicó en el Diario Oficial El Peruano, el Decreto Supremo $\mathrm{N}^{\circ}$ 044-2020-PCM, el cual hasta la fecha se viene prorrogando mediante sucesivas normas, de igual rango, para intentar combatir y en la medida de lo posible reducir los estragos que viene causando el virus. Como venimos señalando, esta crisis se suma a la problemática que se vive en el sistema penitenciario, de acuerdo al informe estadístico reseñado líneas arriba; es notorio que se está viviendo una grave aglomeración, insalubridad y carencia sanitaria en los establecimientos penales de Tumbes a Tacna. Este excesivo agrupamiento poblacional se da en un gran número de veces por un abuso de las prisiones preventivas.

No debemos perder de vista que condenar a una persona a vivir en una celda (que en muchos casos se asemeja a una jaula) es el remedio extremo: es una intervención quirúrgica in extremis del derecho penal cuando ninguna de sus otras medidas cumple la misma función, entre ellas el arresto domiciliario, la condena suspendida y el grillete electrónico. Se hace necesario que en los Tribunales se efectúen ejercicios de ponderación.

La doctrina anota que:

Verdaderamente la ley de ponderación considerada en estricto no establece ningún patrón con cuyo auxilio puedan ser definidos definitivamente las situaciones que se presenten. Pero 
considerada la ponderación como una totalidad nos facilita una posición al establecer un vaso comunicante entre la ley de ponderación con la teoría de la argumentación jurídica racional. La ley de ponderación nos señala qué es lo que debe ser fundamentado racionalmente. (Alexy, 1997 p.67)

Es interesante también mencionar la posición que señala Guastini (2014) al respecto en su libro Interpretar y Argumentar:

Una cosa es balancear (ponderar) dos principios, "sopesarlos". para decidir cuál de los dos -por tener mayor "peso" o valor - debe ser aplicado y cuál en cambio -por tener menor "peso" o valor- debe ser dejado de lado, otra cosa es conciliar dos principios, es decir, "mezclarlos en las justas proporciones", en modo de encontrar una suerte de macro principio que, conciliándolos, los contenga a ambos.

(...).

Si se examina una determinada decisión, se advierte que la ponderación tiene como resultado el sacrificio de uno de los principios en conflicto y la aplicación del otro. No se trata de la aplicación y del sacrificio parcial de ambos. Simplemente, se aplica uno de los principios, mientras que el otro es (momentáneamente) dejado de lado, inaplicado. Hablar aquí de conciliar estaría completamente fuera de lugar. (2014: 219)

\section{LOS MANDATOS DE PRISIÓN PREVENTIVA}

Cuando nos referimos a la prisión preventiva, hay que tener en cuenta que esta es una medida cautelar excepcional para asegurar el espíritu del proceso penal: la readaptación y la resocialización del confinado. Conviene subrayar, su carácter de excepcionalidad y, por lo tanto, siguiendo la definición del término, debe ser aplicada infrecuentemente, sin transgredir los derechos fundamentales de las personas. En primer lugar, los magistrados tienen el deber de verificar que se cumplan copulativamente los requisitos para la aplicación de la misma: i) prognosis de la pena; ii) entorpecimiento a la actividad probatoria y iii) arraigo domiciliario. Luego de ello, deben aún verificar si se dan dos principios elementales del derecho procesal: proporcionalidad y razonabilidad.

Así pues, Bruzzone (2005) citado por Elías (2016. 16) sostenía que la prisión preventiva:

El confinamiento preventivo como solución se hace necesario, para neutralizar los denominados peligros procesales (como son el entorpecimiento de la investigación y fuga), ello para salvaguardar la doble finalidad que reconoce el proceso penal: el descubrimiento de la verdad y la consecución del derecho material. Siempre, a fin de justificar el depósito preventivo de una persona inocente desde el punto de vista del derecho constitucional, pero imputada con elementos concretos como responsable de la realización de un delito (...).

Empero, la realidad del tratamiento de esta figura indica que no se ha acudido a ella de la manera correcta, de parte de los operadores jurídicos facultados de emplear o desaplicar el requerimiento del Ministerio Público. En cuanto al tiempo y circunstancias que nos ha tocado en suerte vivir, hay una aglomeración y exceso de población penitenciaria; más aún, si tenemos en cuenta que un gran número de internos se encuentran solicitando ceses de prisión preventiva, y esto hace que el Poder Judicial haya colapsado por la excesiva carga procesal y no brinde la atención debida en tiempo oportuno a los expedientes judiciales. No debemos olvidar que justicia que tarda no es justicia.

(Barak 2017) citando la Ley de Fundamentación Jurídica de Israel señala lo siguiente: 
Cuando ante una cuestión jurídica que requiere solución, el juez no encuentra respuesta en la ley, en los precedentes o a través de la analogía, debe decidir la cuestión a la luz de los principios de paz, equidad, justicia y libertad de la herencia de Israel.

Ello resulta de suma importancia, ya que el derecho debe integrarse a la realidad social y poner en igualdad de condiciones a las partes en el marco de un debido proceso en sede penal, a fin de concordar y respetar los lineamientos por los cuales se deben direccionar los operadores jurídicos al momento de resolver los casos. Ello conlleva, respetar las garantías procesales desde la etapa de la investigación preliminar.

\section{PROPORCIONALIDAD Y RAZONABILIDAD EN LAS DECISIONES JUDICIALES}

En los tiempos del Barón de Montesquieu se pensaba que el Juez era la boca muda de la ley. Era un simple aplicador del derecho. Lo que no estaba contenido en la norma era simplemente porque el legislador no lo había considerado, y si lo había revisado no tenía relevancia jurídica. Así se manejaba el derecho. Frío. Inconmovible. Sin embargo, a partir de la década del 50 del siglo próximo pasado, comienza a tomar importancia, una nueva teoría jurídica: La teoría de la argumentación jurídica. Se habían producido situaciones no previstas: i) en hornos crematorios se introducían personas vivas para incinerarlas; ii) se asesinaba por asfixia a familias enteras con el tristemente célebre Zyklon B (gas a base de cianuro) tomando como fundamento para tan execrable conducta el insostenible concepto del predominio racial; se había pues generado una contienda directa entre la ley escrita y el derecho natural; entre el positivismo y el iusnaturalismo. Podríamos agregar que no todo es perfecto. Traigamos a colación la frase orwelliana que nos recuerda que la historia la dictan los vencedores. De qué otra forma, podríamos entender entonces que los criminales que dieron la orden de lanzar dos bombas atómicas en las ciudades de Hiroshima y Nagasaki (donde perdieron la vida 110,000 personas sin mencionar los daños colaterales), no hayan sido llevados a tribunales.

Si hay una producción cinematográfica que refleja lo que señala el párrafo precedente, es sin duda alguna: Vencedores y Vencidos. Esta obra de arte data de 1961 y contiene actuaciones magistrales como las de Burt Lancaster, Spencer Tracy, Maximilian Schell, Marlene Dietrich y Judy Garland entre otros. Fue nominada a 12 estatuillas Oscar obteniendo 2 de ellas: mejor actor (Schell) y mejor guion cinematográfico. Relata el caso de cuatro magistrados alemanes que son llevados a juicio por complicidad con la política del régimen nacionalsocialista, en temas de limpieza étnica y esterilización no consentida. Destaca además el rol de Lancaster interpretando al magistrado Ernst Janning, un célebre jurista alemán que traicionando sus ideas, justificó con sus decisiones judiciales, las atrocidades del régimen nacional-socialista.

Es interesante repasar el aporte del futuro Papa Francisco cuando en el marco de sus conversaciones con el rabino Abraham Skorka al referirse al Holocausto apuntaba que:

Hace poco leí -me costó porque me daba náuseas- un libro prologado por Primo Levi que se llama Yo, comandante de Auschwitz, de Rudolf Hoss, un coordinador de ese campo de exterminio que escribió sus memorias estando preso. La frialdad con la que este hombre describe lo que allí pasó demuestra lo demoníaco del asunto. El Demonio se presentó en ídolos que tranquilizaban la conciencia humana. (Bergoglio, 2013 p.168-169)

Había que producir argumentos. Defender conclusiones a base de razones. Es importante diferenciar la interpretación de la integración de la norma jurídica cuando nos referimos a la proporcionalidad y razonabilidad de las decisiones de los operadores jurisdiccionales. La interpretación parte con ventaja sobre la integración. Baste pensar cómo sería un mundo sin leyes. El problema se presenta cuando la norma no da solución al caso. Existen diferentes tipos de interpretación, por ejemplo: i) literal: cuando la misma norma expresa su significado por la claridad 
de su redacción, ii) extensiva: la que mayormente utilizan en los juzgados, iii) exegética: cuando se refiere a un artículo determinado del texto legal; iv) temporal: se da en una línea de tiempo determinada, v) doctrinal: por los juristas; vi) auténtica: la realiza el autor de la norma cuando explica el contenido de la misma, vii) judicial: la que hacen los jueces y se diferencia de las demás por su carácter decisorio, etc.

Pero cuando las interpretaciones no le brindan la respuesta esperada, el juez debe proceder a interpretar: se ha producido un espacio vacío de derecho. Interpretar significa crear, y se crea recurriendo a las fuentes formales del derecho (doctrina, jurisprudencia y costumbre) de la mano de dos criterios fundamentales que se utilizan en el derecho procesal: la proporcionalidad y la razonabilidad.

Entender que en la mayoría de las veces los jueces tienen casos sencillos de resolver en los que les basta con hacer una justificación interna de sus decisiones aplicando un silogismo donde el primer y mayor supuesto es la norma, el menor el hecho o conducta y la conclusión se desprende de la interacción entre ambas; pero que cuando la mano viene más brava hay que realizar una externa en la que se hace necesario ponderar recurriendo a las fuentes formales del derecho.

Existen tratadistas que se encuentran en la vereda opuesta y son críticos de la ponderación. Así podemos a mencionar a García quien en su obra Decidir y Argumentar sobre Derechos señala lo siguiente:

La teoría de la ponderación, tal como la entienden otros tratadistas como Alexy y tantos otros, está inexorablemente adherida a la concepción del derecho que niega la separación entre derecho y moral, ya que considera que la naturaleza esencial o última del derecho es moral, tomando en cuenta que el razonamiento jurídico es un caso singular del razonamiento práctico general y que siempre deben y pueden las razones para la decisión resultantes de la norma jurídico-positiva ponderarse o cotejar con las razones morales en general. Caiga quien caiga. (García, 2017, p. 67)

Sin embargo, esta postura, respetable no la compartimos. Dentro de las ciencias sociales, el Derecho viene a ser más relativa de todas. Aquí nada es absoluto. Todo es relativo. Podríamos citar a la cantautora folclórica argentina cuando nos recuerda que todo cambia, incluso lo superficial y que ella cambie no es extraño. En tiempos críticos que atraviesa la humanidad, donde las reglas son muchas veces superadas por los principios, es interesante la opinión que nos regala Guastini en su libro Discutiendo. Nuevos estudios de teoría y meta teoría del derecho.

En suma, la fundamentación de los derechos humanos debe buscarse en algún ordenamiento normativo. Pero sí, por otra parte, el ordenamiento en cuestión no puede ser un ordenamiento positivo -bajo pena de renuncia a la generalidad y protección de los derechos humanosentonces no queda que dirigirse al derecho natural. (Guastini, 2019 p.226)

Esa misma postura la sostiene Barak cuando al referirse a la segunda etapa del control constitucional en su búsqueda de una razón que permita justificar la restricción de un derecho nos explica que:

El enfoque básico es que los derechos humanos consagrados en la constitución no son "absolutos"; sino, por el contrario, relativos. Ellos pueden ser objeto de restricción. La restricción es constitucional solo si tiene una justificación jurídica. La justificación se encuentra en las reglas de la proporcionalidad, que hacen parte de la cláusula restrictiva. (Barak, 2017 p.479) 


\section{TRATAMIENTO DE LA PRISIÓN PREVENTIVA}

Según el Boletín Estadístico Institucional del Ministerio de Justicia (2019), con relación a la situación jurídica de la población que se encuentra en establecimientos penitenciarios el $60.01 \%$ $(51,745)$ se encuentra sentenciada mientras el $39.99 \%(34,484)$ se encuentra procesado en espera que se defina su situación jurídica. Podríamos referirnos a la gran cantidad de internos que se encuentran privados de su libertad por una mala aplicación del mecanismo de la prisión preventiva. Se hace impostergable que los jueces y fiscales apliquen correctamente los principios de proporcionalidad y razonabilidad. Con más razón, si nos atenemos al hecho que el Derecho Penal es de mínima intervención y la prisión es la excepción. Existen otros medios que a disposición del Operador Judicial faculta que la potestad sancionadora del Estado cumpla con su cometido. Cabría preguntarse, si el escenario sería el mismo: si jueces y fiscales pasarán una noche encerrados en el pabellón de máxima peligrosidad de una prisión, y comprendieran lo que ello implica.

Los Operadores Judiciales cuentan con una norma explícita que les señala que es lo que se debe hacer. El artículo $255^{\circ}$ del Código Procesal Penal, indica claramente que hay una facultad oficiosa de los jueces de revisar de oficio las prisiones preventivas.

En la misma línea, hay un mandato convencional para situaciones similares como la sentencia recaída en el caso Carranza Alarcón contra Ecuador, expedida por la Corte Interamericana de Derechos Humanos -el más alto tribunal en la región interamericana e intérprete máximo de la Convención Americana sobre Derechos Humanos- donde se determina que los estados tienen que hacer revisiones periódicas de dichos mandatos. Esto quiere decir que, cada cierto tiempo los jueces tienen que revisar el conjunto de fallos de prisión preventiva y evaluar si la misma se mantiene o se deja sin efecto.

\section{EL HACINAMIENTO PENITENCIARIO Y EL CORONAVIRUS}

Esta pandemia ha generado alarma alrededor del mundo. Estamos viviendo una crisis sanitaria que no hace diferencia de raza, sexo, cultura y que tampoco distingue billeteras y monederos. En ese escenario, el Estado Peruano se ha visto en la obligación de implementar medidas necesarias para frenar la propagación del COVID-19.

El 15 de marzo del presente año se publicó el Decreto Supremo Nº44-2020-PCM, que hasta la fecha se viene prorrogando mediante sucesivas normas de igual rango para tratar de combatir y en la medida de lo posible detener los estragos que viene causando el virus. Como venimos señalando esta crisis se suma a la problemática que se vive en el sistema penitenciario, de acuerdo al informe estadístico reseñado líneas arriba; es notorio que se está viviendo una grave aglomeración, insalubridad y carencia en los establecimientos penales de Tumbes a Tacna.

\section{LA URGENCIA DE BUSCAR SOLUCIONES PROCESALES}

Cuando se tiene un sistema de justicia deficiente y, se está frente a una situación extraordinaria como es la pandemia del COVID-19, es importante dar soluciones efectivas y aplicables para el momento en el que se vive. Es pertinente partir de que, en esta situación, no es factible y realista dar soluciones para los condenados por delitos graves. Por ello, cabe resaltar que el tema de discusión son las personas procesadas que se encuentren confinadas en un centro de readaptación social o los casos contemplados en el Decreto Supremo N. ${ }^{\circ}$ 004-2020-JUS. Ahora bien, las soluciones que los autores proponen no pueden ser dadas desde el ámbito del derecho penal, sino más bien del constitucional. 
Por un lado, la respuesta la pueden brindar jueces y fiscales. Precisamente, si nos situamos en el lugar de los presos preventivos, se tiene que tener en cuenta que se está en un contexto diferente al de hace unos meses. Contexto que ya de por sí era difícil. Es así que la flexibilidad del proceso se tiene que ver, pero no para relativizar garantías, sino al contrario, para salvar vidas.

En otras palabras, los jueces, en situaciones no ordinarias, deben resolver de acuerdo a la realidad, sin involucrar a otras instituciones, dado que, como ya se ha analizado, el sistema penitenciario no está funcionando, así como el Estado, no está actuando con eficiencia en todos sus ámbitos. El hecho, es simple, se está viviendo una pandemia letal. Esto, sumado a todas las deficiencias que hay, debe ser suficiente para que los jueces opten por la vida de los procesados.

Podemos citar al maestro del Derecho Civil italiano Piero Calamandrei cuando apuntaba que los jueces más que aplicar el derecho, se deben preocupar por buscar la justicia.

El tratadista Figueroa (2019) se refiere a ello cuando señala lo siguiente:

La tesis de la unidad del razonamiento práctico no implica la tesis de la unidad de respuesta correcta (en otras palabras, la tesis del caso especial es independiente de la tesis de la única respuesta correcta). Que en sus respuestas los jueces hayan de recurrir a argumentos legales y morales, no significa que exista una única respuesta correcta a las controversias planteadas. Si adoptamos una teoría ética constructivista, entonces debemos aceptar que las respuestas que nos proporciona el discurso moral son dependientes hasta cierto punto de un contexto, singularmente de los participantes en este discurso moral y si los participantes pueden variar a lo largo del tiempo, también podrán variar las respuestas a nuestros problemas prácticos. La objetividad moral que se incorpora a los argumentos legales no implica respuestas absolutas. (2019, p. 192).

\section{LA IMPORTANCIA DEL HÁBEAS CORPUS CORRECTIVO}

En palabras de Díaz (2008) citado por Aldana (2016) en la época contemporánea, el hábeas corpus, despliega su campo a situaciones en las cuales, existiendo, prima facie, orden de autoridad competente, se puede originar una ilegítima agravación de la privación de la libertad o del cumplimiento de las condiciones penitenciarias. En consecuencia, la modalidad mencionada de hábeas corpus ha sido establecida ya no para refutar la ilegalidad, arbitrariedad o inconstitucionalidad de una privación o restricción a la libertad física - derecho fundamental originariamente tutelado a través de dicho proceso-, sino para cuestionar las condiciones en que se efectiviza la referida privación o restricción.

A la luz de lo anterior, es crucial establecer cuál es el acto lesivo. El mismo que como eje de la discusión en un proceso constitucional, se encuentra configurado en la violación a la salud o la amenaza a la salud. La lectura del artículo 34.2 del Código Procesal Constitucional Peruano, respecto al contenido de sentencia fundada, establece que cuando un juez declara fundada una demanda de hábeas corpus correctivo, este debe responder que se cambien las condiciones de la detención. Cuestión que, en la práctica, no está ocurriendo. Se debe tomar en cuenta que la norma establece que la norma señala que el cambio sea en el mismo establecimiento penitenciario o en otro.

Comentarios a la norma en el Código Procesal Constitucional señala lo siguiente:

De esta forma, el hábeas corpus correctivo opera para situaciones relativas a tratos crueles, humanos o degradantes dentro de un establecimiento penitenciario, el derecho a la salud del interno, las visitas y comunicaciones con el exterior, el derecho de la libertad sexual de los reclusos, el derecho a la educación, la libertad religiosa y el derecho de defensa en el sentido de las condiciones en que el interno y su abogado defensor interactúen. (Salas, 2015: 390) 
De ahí que el razonamiento del operador jurídico (en este caso, el juez) debe tener en cuenta, todas y cada una de las reglas de la sana crítica que se está afectando el derecho a salud del procesado. Derecho que de acorde a la Constitución Política debe ser protegido por todas las autoridades nacionales.

\section{LA IMPORTANCIA DEL CESE DE LAS PRISIONES PREVENTIVAS}

Al referirse al cese de las prisiones preventivas señala lo siguiente:

La suspensión de la medida de prisión preventiva (la que muchas veces configura un adelanto de la decisión final del juzgador), procederá cuando existan nuevos elementos de convicción que permitan comprobar que no concurren los motivos que determinaron su imposición y a la vez necesario variarla por una medida de comparecencia. Para la determinación de la medida sustitutiva el operador jurisdiccional tendrá en cuenta, además, las características personales del procesado, el tiempo transcurrido desde la privación de la libertad y el estado de la causa. (Urbano, 2018 p.46)

En una situación de crisis, un elemento de convicción procesal, debe ser el que está ocurriendo a vista de todos: el COVID-19. Y apartarse de los formalismos, como tener que presentarlo por mesa de partes. Ahora, en una medida de coerción como es la prisión preventiva, no se tiene solo ese elemento. Está también el análisis del peligro procesal, el cual, si bien es cierto, no ha desaparecido, es evidente que ha disminuido. Asimismo, lo que se debe hacer, es analizar los casos, sobre todo donde hay medidas de coerción impuestas, conjuntamente con la proporcionalidad. En tiempos así, no solamente, se trata de la libertad de los procesados, sino, ahora, también de salud. Nos encontramos ante un claro caso de lo que comentábamos líneas arriba: las reglas contra los principios.

Manuel Atienza (2018) respondiendo epistolarmente a la posición de su amigo Juan Antonio García Amado contenida en la obra Un Debate sobre la Ponderación lo explica del siguiente modo:

Tú pareces pensar que las reglas (a diferencia -supongo- de los principios) no tienen excepciones implícitas, esto es, que todas las excepciones están dadas de antemano, han sido previstas por el legislador, y en eso ves una ventaja decisiva en relación con la manera de operar (con principios) a través de la ponderación (...)

\section{$(\ldots)$}

Bueno. La idea de que las reglas no pueden ser derrotadas (si sólo tienen las excepciones establecidas por el legislador -las excepciones son "finitas y conocidas"-, ello equivale a negar que puedan ser "derrotadas", en el sentido en el que hoy suele usarse esa expresión) me parece muy difícil de defender y, en caso de hacerse, ello conduciría a una concepción de tal rigidez que dudo pueda ser la tuya. (2018, pp.102-104)

En esa misma línea, Cinciardo (2004) citado por Cárdenas (2017) frente al principio de razonabilidad, sucedáneo al actual juicio de proporcionalidad, señala que en el moderno derecho constitucional se presentan, con permanencia, situaciones que engloban derechos fundamentales y bienes públicos que aparecen en disputa, es así que le corresponde al operador jurisdiccional precisar mediante una decisión razonable y armónica en qué grado prevalece el uno sobre el otro, que resulte satisfactoria para las partes en conflicto y para el espacio social en la que se debate, en otras palabras, es necesario realizar un juicio de ponderación o equilibrio entre los valores en conflicto. 
Siguiendo esa línea, en una situación de emergencia los jueces tienen que cambiar la dinámica del razonamiento frente a los hechos nuevos y tener en cuenta que este elemento nuevo es notorio y público, por lo tanto, no se necesita de alguna forma de prueba. Se está tratando de una pandemia, un riesgo a un derecho fundamental: el más importante de todos: la vida humana, el cual no es mezquino, y no está derogado, a pesar de que se esté en un estado de emergencia.

\section{MECANISMO DE CONVERSIÓN DE LA PENA}

El tema actual de crisis sanitaria debería ser suficiente para los agentes jurídicos, al momento de resolver los casos en los que se encuentran las personas procesadas. Más aún si se refiere a algo que no debería ser discutido, puesto que se trata de una cuestión de vida. Ahora, tal como señala Vega (2017.100):

La conversión es un mecanismo alternativo que reemplaza la imposición de una pena privativa de libertad por otra de distinta naturaleza. La lógica de esta alternatividad punitiva es evitar el excesivo efecto negativo que generaría la imposición de una pena privativa de libertad de corta o mediana duración, respecto a conductas que no afectan significativamente la convivencia social y la seguridad colectiva. Siendo los requisitos: i) que no sea procedente la condena condicional o la reserva del fallo condenatorio; y, ii) que la pena privativa de libertad a imponer al condenado no sea superior a cuatro 4 años.

Por tanto, esta es una manera de evitar el incremento de hacinamiento de personas en las cárceles, lo cual ya es una problemática que merece atención de las autoridades nacionales, especialmente, en una situación de crisis como la que se vive. Es así, que los jueces tienen una gran responsabilidad al momento de resolver los casos en situaciones de emergencia. El derecho, en general, en nuestros tiempos, no es inmune a la Constitución. Sino por el contrario, como dice Zagrebelsky en este brillante libro, El derecho dúctil. Ley, derechos, justicia (2016), el derecho invade todos los ámbitos y todos los fueros del ordenamiento jurídico. No hay parcela, no hay espacio u ordenamiento jurídico específico que no deba o esté condicionado a los mandatos de la Constitución.

Para dar solución al problema presente analizado, en principio, se debe plantear la situación en la que se encuentra dicho problema, en este caso, es que estamos viviendo una situación de anormalidad constitucional, un régimen de excepción que es el estado de emergencia, y que, por motivos que amenazan la salud pública de la nación, se han tenido que restringir ciertos derechos, empero no los fundamentales. El artículo 137 numeral 1 de la Constitución Política del Perú, es bastante claro, nos indica que en un estado de excepción como el estado de emergencia, únicamente, se restringe o suspende el ejercicio de derechos constitucionales relativos a la libertad y la inviolabilidad del domicilio, la seguridad personal, y la libertad de tránsito y de reunión en el territorio. No hay otro más. Por ende, no existe ningún derecho fundamental que entre dentro de este artículo. Hay derechos que son inderogables en tiempos de catástrofe y normalidad, en tiempos ordinarios y no ordinarios, derechos tales como los siguientes: el derecho a la dignidad, a la integridad, el cual este último ya ha sido desarrollado, por ejemplo, por la Convención Interamericana de Derechos Humanos, en el artículo 5.2: Ninguna persona puede ser sometida a torturas ni a penas o tratos crueles, inhumanos o vejatorios. Toda persona privada de libertad será tratada con el respeto debido a la dignidad inherente al ser humano. Así, en circunstancias actuales, con un sistema penitenciario en crisis y emergencia, declarado oficialmente desde hace años, con un hacinamiento y una sobrepoblación desbordante, se tiene que respetar los derechos inherentes a las personas, sin excluir por cualquier condición, como son la dignidad e integridad. De lo contrario, si el Estado no toma medidas, convierte a las personas involucradas en estos problemas, en completos desechos. Los jueces, por su parte, deben ser aplicadores de justicia constitucionales, no especializados. Puesto que, son ellos los que preconizan y enarbolan la bandera de la dignidad de aquel ser humano desdichado que está preso 
mientras un proceso dura o mientras se ejecuta su condena. Ambos, merecen el mismo respeto a que no se les someta a una pena o trato cruel y degradante a su persona.

\section{LAS GRACIAS PRESIDENCIALES}

El Artículo 118, numeral 21 de nuestra Constitución Política, establece que el Presidente de la República se encuentra en la facultad de "conmutar penas y conceder indultos". Ejercer el derecho de gracia en apoyo a la situación legal de los procesados en los casos en que la etapa de instrucción haya excedido el doble de su plazo más su ampliatoria".

Fliquete, (2017) citado por Pastor (2019) sostenía que:

El derecho de gracia es una manifestación de benevolencia de parte de quien tiene la investidura de poder, el cual materializa el perdón. Es así que, el derecho de gracia requerirá, como consecutivo, la comisión anterior de un hecho punible, que establece la imposición de un castigo, capaz de ser perdonado. (p. 19)

Ante la dantesca situación que estamos viviendo, el Estado Peruano ha tomado las medidas respectivas para frenar los avances de este letal virus; es por ello que, a lo largo de este confinamiento se han promulgado diferentes Decretos Legislativos que buscan salvaguardar la Integridad del grupo social, incidiendo en la población de más bajos recursos. Sin embargo, la población penitenciaria no está fuera de asumir la propagación de la pandemia, sino que más bien lo más probable es que la misma se propague por las condiciones propicias que se le presentan.

En ese contexto, la Presidencia de la República a través del Decreto Supremo Nº04-2020-JUS publicado el 23 de abril de 2020 considera situaciones excepcionales para la propuesta y evaluación de recomendación de Gracias Presidenciales, y determina su procedimiento, en el marco de la emergencia sanitaria por Covid-19, estableciendo en su artículo 3.1 los siguientes supuestos para la obtención de la conmutación de pena e indulto común:

a) Que se trate de la progenitora y continúe con su niña o niño dentro de la prisión.

b) Que la madre se encuentre gestando.

c) Que se cumpla en los próximos seis meses la condena, efectiva o redimida.

d) Que se haya condenado al confinado una pena de cárcel no mayor a cuatro años.

e) Que se trate de un adulto mayor a 60 años que $n$ haya incurrido en la comisión de delito grave.

En ese orden de ideas, se tiene que en el literal 3.2 se agrega que para acceder al beneficio se debe cumplir además con las siguientes condiciones:

a) Tener la condición de primario.

b) No registrar condenas por otros delitos y/o no registrar medida de detención a nivel nacional.

c) No contar con prohibición legal expresa.

La norma también prescribe el procedimiento para obtener la gracia y consigna expresamente en que tipos penales se restringe el beneficio, a saber:

a) Delitos contra la Vida, el Cuerpo y la Salud.

b) Delitos contra la Familia.

c) Delitos contra la Libertad.

d) Delitos contra el Patrimonio.

e) Delitos contra la Seguridad Pública.

f) Delitos Contra la Tranquilidad Pública. 
g) Delitos Contra la Humanidad.

h) Delitos contra los Poderes del Estado y el orden Constitucional.

i) Delitos contra la Administración Pública.

j) Terrorismo.

k) Financiamiento al Terrorismo.

l) Lavado de Activos y;

m)Delitos cometidos por Violencia contra la Mujer e integrantes del Grupo Familiar.

Cabe señalar que esta norma es solo para los sentenciados, no contempla los casos de aquellos que están purgando prisión preventiva, es por ello que se plasma de acuerdo a un estudio estadístico realizado por el INPE en el que se distingue entre personas procesadas y personas sentenciadas. Mediante este cuadro (INPE 2018) se puede ver cuáles son los delitos más representativos, haciendo la salvedad que solamente algunos de ellos, se harían merecedores de obtener el beneficio residual de las gracias presidenciales.

POBLACIÓN PENAL POR DELITOS ESPECÍFICOS SEGÚN SITUACIÓN JURÍDICA

\begin{tabular}{|c|c|c|c|}
\hline DELITO & TOTAL & PROCESADO & SENTENCIADO \\
\hline Total General & 90,934 & 35,717 & 55,217 \\
\hline ROBO AGRAVADO & 23,715 & 9,355 & 14,360 \\
\hline VOLACION SEXUAL DE MENOR DE EDAD & 8,843 & 2,993 & 5,850 \\
\hline TRAFICO IUCTTO DE DROGAS & 7,761 & 3,087 & 4,674 \\
\hline ROBO AGRAVADO GRADO TENTATNA & 4,628 & 1,917 & 2,711 \\
\hline PROMOCION O FAVORECIMENTO AL TRAFICO IUCCTO DE DROGAS & 4,533 & 2,087 & 2,446 \\
\hline VIOLACION SEXUAL & 4,157 & 1,078 & 3,079 \\
\hline TRAFICO ILICTO DE DROGAS - FORMAS AGRAVADAS & 3,487 & 1,097 & 2,390 \\
\hline HOMICIDIO CAUIICADO - ASESINATO & 2,955 & 931 & 2,024 \\
\hline TENENCIA ILEGAL DE ARMAS & 2,919 & 1,159 & 1,760 \\
\hline HURTO AGRAVADO & 2,892 & 1,072 & 1,820 \\
\hline INCUMPUMENTO DE LA OBLIGACION AUMENTARIA & 2,684 & 988 & 1,696 \\
\hline ACTOS CONTRA EL PUDOR EN MENORES DE 14 AÑOS & 2,261 & 887 & 1,374 \\
\hline MCROCOMERCIALIZACION O MICROPRODUCCION & 1,492 & 620 & 872 \\
\hline HOMICIDIO SIMPLE & 1,492 & 467 & 1,025 \\
\hline ACTOS CONTRA EL PUDOR & 1,470 & 584 & 886 \\
\hline HURTO AGRAVADO - GRADO TENTATIVA & 1,239 & 361 & 878 \\
\hline EXTORSION & 1,136 & 446 & 690 \\
\hline ASOCIACION IUCITA PARA DEUNQUIR & 812 & 695 & 117 \\
\hline SECUESTRO & 771 & 254 & 517 \\
\hline LESIONES GRAVES & 738 & 254 & 484 \\
\hline OTROS DELTOS & 10,949 & 5,385 & 5,564 \\
\hline
\end{tabular}

Fuente: Unidades de Registro Penitenciario

Elaboración: INPE/Unidad de Estadística

Tras revelar los datos estadísticos se distingue que solo podrían ser beneficiadas las personas sentenciados por los delitos de tráfico ilícito de drogas, promoción o favorecimiento del mismo, hurto agravado, incumplimiento de la obligación alimentaria, micro comercialización o micro producción y hurto agravado en el grado de tentativa.

Aunque, para determinar a quienes se les concederá estas gracias presidenciales, se tendrá que verificar, al detalle, las sentencias y demás documentos que forman el legajo personal de cada confinado; lo cual es contraproducente puesto que ello demandará un tiempo considerable y en estos momentos este resulta ser el mayor problema. 
En ese orden de ideas, son 68 penales en todo el Perú y es preocupante que estas medidas no lleguen a todos los reos y la reacción por parte de las autoridades sea demasiado tarde frente a esta pandemia que arrasa día a día con la población mundial. Ante la realidad que afrontan las personas procesadas, se tiene en cuenta que hacen falta medidas excepcionales inmediatas para estos reclusos, ya que si bien es cierto se han planteado posibles soluciones es menester que las autoridades en conjunto tomen acciones efectivas sobre el caso y puedan responder con prontitud al clamor de esta población vulnerable.

Las medidas presentadas por el Ejecutivo, no son lo suficientemente rápidas para actuar ante este letal virus, los estragos producidos por esta pandemia se hacen notar. Somos testigos de cómo se está acabando la vida de estas personas si los encargados de hacerlo no toman las medidas necesarias a tiempo. Aunque el Presidente de la República opte por otorgar las gracias presidenciales y pueda reducir en cierta medida la población penitenciaria, no servirá de nada si se sigue tardando en poner en la práctica lo planteado.

Por tal motivo queda claro que estas medidas debieron ser planteadas con prontitud, apenas fue dictado el estado de emergencia-, el generar esta prolongación hace que más reclusos y trabajadores sigan pasando penurias ante el estado de insalubridad que viven en cada centro penitenciario ya que es evidente que las cárceles son un foco infeccioso de alta gravedad.

Al momento en que estamos redactando el artículo, se ha hecho pública la información de que ya son más de 180 internos los que han fallecido de coronavirus en los penales. En ese contexto, el Presidente Vizcarra ha criticado con dureza a los padres de la patria por no haber brindado una salida rápida al problema del hacinamiento en los penales y siendo ello así, solicitará al Congreso de la República se le brinden las facultades que le permitan adoptar medidas que conduzcan a : i) evitar nuevos casos de coronavirus y ii) contribuir a disminuir los niveles de hacinamiento en los centros de readaptación social, que a la fecha son cualquier cosa menos eso.

En una presentación ante los medios de comunicación el Presidente manifestó según anota (El Comercio 20/05/20) lo siguiente:

El Congreso desestimó (el proyecto para deshacinar los penales), se abstuvo, en la votación ganó la abstención, que es una forma de decir "mejor no toco el tema", "no veo el problema", (pero) el problema está ahí y hay que darle una solución. Hemos tomado la decisión (de pedir facultades), manifestó en conferencia de prensa.

En ese orden de ideas el Poder Ejecutivo ha formulado el Proyecto de ley 5110-2020 como propuesta a las medidas de hacinamiento en los penales:

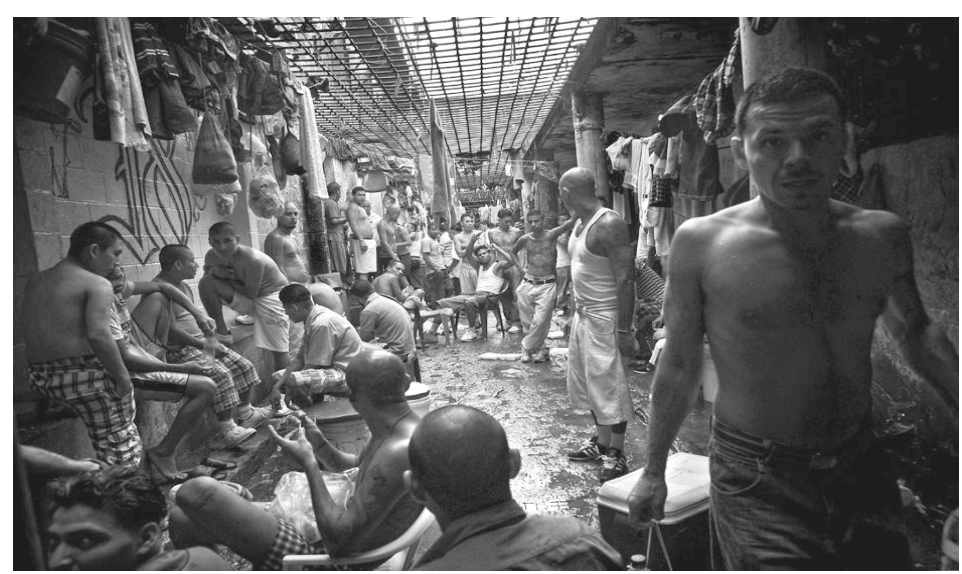

Imagen referencial 
PROYECTO DE LEY 5110-2020

Medidas de deshacinamiento en penales

\begin{tabular}{|c|c|c|}
\hline PROPUESTA & $\begin{array}{l}\text { INTERNOS A LOS QUE } \\
\text { SE APLICARÍA }\end{array}$ & $\begin{array}{c}\text { MEDIDAS } \\
\text { ADICIONALES }\end{array}$ \\
\hline \multirow{5}{*}{$\begin{array}{c}\text { CESE DE } \\
\text { LA PRISIÓN } \\
\text { PREVENTIVA } \\
\text { PARA DELITOS NO } \\
\text { GRAVES }\end{array}$} & $\begin{array}{l}\text { 1. Presos con medida } \\
\text { preventiva que no estén } \\
\text { siendo procesados por } \\
\text { delitos graves }\left(^{*}\right) \text {. }\end{array}$ & \multirow{5}{*}{$\begin{array}{l}\text { Se impone } \\
\text { comparecencia con } \\
\text { restricciones }\end{array}$} \\
\hline & $\begin{array}{l}\text { 2. Presos que no tienen sentencia } \\
\text { condenatoria con pena privativa } \\
\text { de libertad vigente. }\end{array}$ & \\
\hline & $\begin{array}{l}\text { 3. Presos a quienes se haya } \\
\text { prolongado la orden de prisión } \\
\text { preventiva }\left({ }^{*}\right) \text {. }\end{array}$ & \\
\hline & $\begin{array}{l}\text { 4. Mujeres gestantes o con hijos } \\
\text { menores a } 3 \text { años. }\end{array}$ & \\
\hline & 5. Personas mayores a 65 años $\left(^{*}\right)$. & \\
\hline \multirow{3}{*}{$\begin{array}{l}\text { Revisión de la prisión } \\
\text { preventiva para } \\
\text { delitos graves }\left(^{* *}\right)\end{array}$} & $\begin{array}{l}\text { 1. Presos que cuenten } \\
\text { con prisión preventiva } \\
\text { ampliada, sin fecha } \\
\text { programada y modificada } \\
\text { para el juicio oral. }\end{array}$ & \multirow{3}{*}{$\begin{array}{l}\text { Se impone una } \\
\text { medida que asegura } \\
\text { la presencia del } \\
\text { infractor en el } \\
\text { proceso. El domicilio } \\
\text { donde se cumple la } \\
\text { medida no puede ser el } \\
\text { mismo donde reside la } \\
\text { víctima del delito por el } \\
\text { que se le procesa }\end{array}$} \\
\hline & $\begin{array}{l}\text { 2. Presos incluidos en el grupo } \\
\text { de personas vulnerables con } \\
\text { especial riesgo al COVID - 19, } \\
\text { según el MINSA. }\end{array}$ & \\
\hline & 3. Madres con hijos & \\
\hline $\begin{array}{c}\text { Conversión de la } \\
\text { pena privativa de } \\
\text { libertad a pena } \\
\text { de prestación } \\
\text { de servicios a la } \\
\text { comunidad para } \\
\text { condenados a penas } \\
\text { no mayores de } 8 \\
\text { años }\left(^{*}\right) .\end{array}$ & $\begin{array}{l}\text { Se excluyen los sentenciados por los } \\
\text { delitos: Contra la vida, el cuerpo y } \\
\text { la salud; omisión de prestación de } \\
\text { alimentos, contra la libertad, contra } \\
\text { el patrimonio, contra la seguridad } \\
\text { pública, contra la tranquilidad } \\
\text { pública, contra la humanidad, } \\
\text { contra los poderes del Estado y } \\
\text { el orden constitucional, contra la } \\
\text { administración pública, terrorismo y } \\
\text { lavado de activos. }\end{array}$ & $\begin{array}{c}\text { Se impondrán reglas de } \\
\text { conducta por un plazo } \\
\text { de } 2 \text { a } 5 \text { años. En casos } \\
\text { más graves, se dictará } \\
\text { vigilancia electrónica } \\
\text { personal. }\end{array}$ \\
\hline
\end{tabular}

(*) Con excepción de los delitos: terrorismo; contra la vida, el cuerpo y la salud; contra la libertad; contra el patrimonio; contra la seguridad pública; contra la tranquilidad pública; contra la humanidad; contra los poderes del Estado y el orden constitucional; contra la administración pública y lavado de activos. 


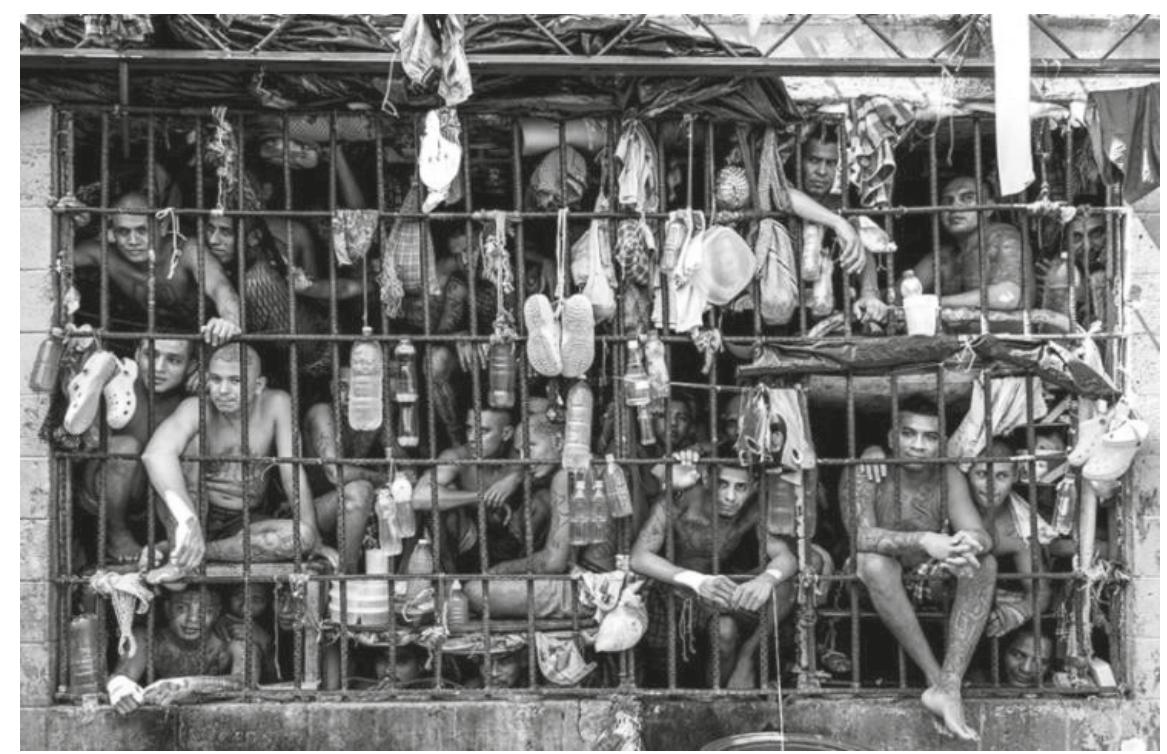

Imagen referencial

Medidas de deshacinamiento en centros juveniles

\begin{tabular}{|c|c|}
\hline PROPUESTA & INTERNOS A LOS QUE APLICARÍA \\
\hline $\begin{array}{c}\text { Cese de la medida de internación } \\
\text { preventiva. }\end{array}$ & $\begin{array}{c}\text { Internos preventivos, siempre y cuando la } \\
\text { medida no haya sido impuesta por delitos } \\
\text { contra la vida, el cuerpo y la salud; delitos } \\
\text { contra la libertad; delitos contra el patrimonio } \\
\text { y terrorismo. }\end{array}$ \\
\hline $\begin{array}{c}\text { Variación de la medida socioeducativa de } \\
\text { internación por la sanción de prestación de } \\
\text { servicios a la comunidad. }\end{array}$ & $\begin{array}{c}\text { Internos con medidas de internación no } \\
\text { mayor de seis años. }\end{array}$ \\
\hline
\end{tabular}

$\left({ }^{*}\right)$ Con excepción de los delitos: terrorismo, contra la vida, el cuerpo y la salud; contra la libertad y contra el patrimonio.

FUENTE: Diario El Comercio (20.05.20)

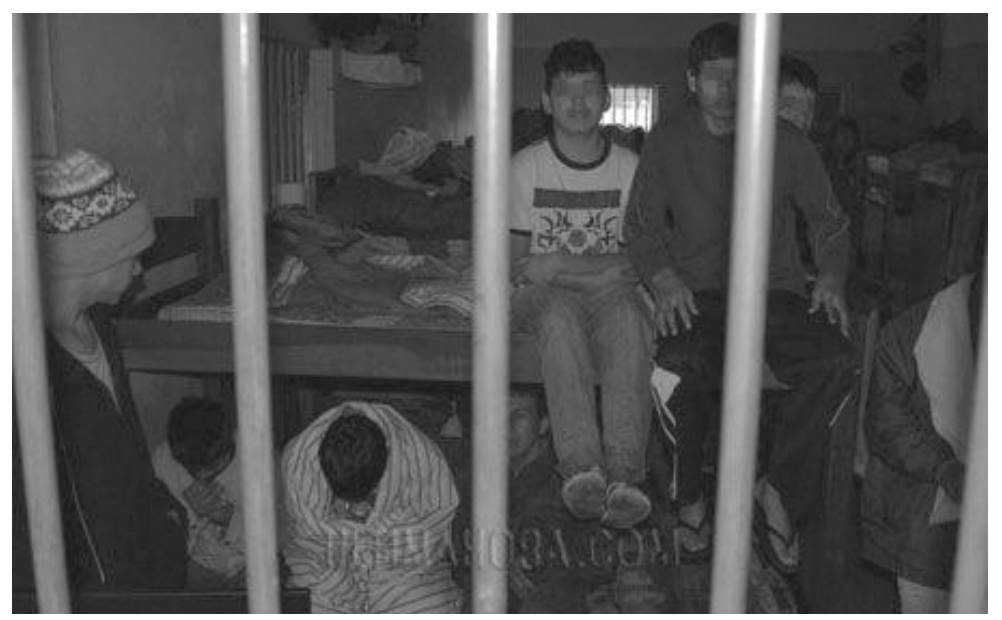

Imagen referencial 


\section{CONCLUSIONES}

1. Frente a la crisis sanitaria de la pandemia del COVID-19, se deben implementar las medidas necesarias para combatir este letal virus y salvaguardar la vida e integridad tanto de los reos como de los trabajadores del Instituto Penitenciario. Ante ello, es importante señalar que el Estado peruano debe impulsar a la correcta aplicación de los mecanismos procesales que ayuden a la reducción de la población penitenciaria, esta medida permitirá que se pueda lograr evitar los hacinamientos en los penales y la condición de insalubridad en que viven día a día los confinados. Anteriormente se han realizado estudios que le han demandado una fuerte inversión a las arcas estatales y que no nos han conducido a nada. Se hacían proyecciones sin el menor sustento técnico que luego con el transcurso del tiempo quedaba demostrada que no servían para nada, mientras tanto el problema seguía agudizándose. Ocurría lo de siempre. Para que comencemos a hacer algo como país es necesario que primero recibamos el golpe, lamentablemente no existen políticas previsionales.

2. A través del Decreto Supremo No004-2020-JUS se dispone evaluar y otorgar gracias presidenciales tales como el indulto humanitario y común, así como la conmutación de las penas. Sin embargo, estas medidas solo benefician a los reclusos sentenciados, por lo cual, la población restante (personas procesadas) seguirá pasando penurias en los centros penitenciarios frente a esta crisis sanitaria. Se debe tener en cuenta el correcto uso de la prisión preventiva como medida cautelar excepcional y así garantizar los fines del proceso penal. El eterno problema de la colisión entre reglas contra los principios; estos últimos están recogidos en la Carta Fundamental del Estado que señala que todos somos iguales ante la ley sin que se admita diferencias por razones de raza, sexo, religión o de cualquier otra índole.

3. Lamentablemente, los Congresistas de la República no están a la altura de las circunstancias. Han demostrado una inacción y pasividad alarmantes ante el problema pandémico que ha traído como consecuencia lamentables pérdidas de vidas humanas, específicamente en la población penitenciaria. Ante esta inacción de nuestros parlamentarios, el Poder Ejecutivo, a pesar de lo anotado en la conclusión anterior, se ha visto en la necesidad y obligación de formular un proyecto de ley, el cual se centre en las gestiones de deshacinamiento en los penales y en los centros juveniles a base de un criterio de revisión de los tipos penales por los que se encuentra purgando condena la población objetiva, resguardando siempre la seguridad del grupo social ante la salida de internos. Lo que corresponde es que el mismo se aplique correctamente por los agentes encargados del mismo. Ojalá no ocurra el cuento de nunca acabar: normas tenemos de sobra, el problema es generado por los que inciden sobre ellas.

\section{REFERENCIAS}

- Alexy, R. (1997). Teoría de los Derechos Fundamentales. Madrid, España: Centro de Estudios Constitucionales. Traducción de E. Garzón

- Atienza, M. y García, J (2018). Un debate sobre la ponderación. Sucre, Bolivia: Tribunal Constitucional Plurinacional de Bolivia.

- Barak, A. (2017). Proporcionalidad. Los Derechos Fundamentales y sus restricciones. Lima, Perú: Palestra Editores.

- Bergoglio. J. y Skorka, A. (2013). Sobre el cielo y la tierra. Las opiniones del papa Francisco sobre la familia, la fe y el papel de la Iglesia en el siglo XXI. Buenos Aires, Argentina: Editorial Sudamericana.

- Carranza Alarcón con Ecuador (2020). Corte Interamericana de Derechos Humanos, 3 de febrero del 2020 (sentencia sobre el plazo razonable de la prisión preventiva). 
- Cisneros, J. W. V. (2017). La conversión de la pena privativa de la libertad y el novísimo artículo 52- A del Código Penal. pdf.

- Da Rosa, T, García, J. y García A. (2019). Teoría de la Argumentación Jurídica. Principio de Proporcionalidad y Racionalidad de las Decisiones Judiciales. Lima, Perú: Ediciones Legales. Traducción de Juan Carlos Panéz Solorzano.

- García, J. (2017). Decidir y argumentar sobre Derechos. Colección: “Jueces y Argumentación Jurídica". Ciudad de México, México: Tirant Lo Blanch

- Guastini, R. (2019). Discutiendo. Nuevos estudios de teoría y metateoría del derecho. Lima, Perú: Zela Grupo Editorial.

- Guastini, R. (2014). Interpretar y Argumentar. Madrid, España: Centro de Estudios Políticos y Constitucionales. Traducción de Silvina Álvarez Medina.

- Guastini, R. (2016). La sintaxis como derecho. Madrid, España: Marcial Pons.

- Martínez Martínez, Faustino. (2005). Zagrebelsky, Gustavo, El derecho dúctil: Ley, derechos, justicia (Traducción de Marina Gascón, $5^{a}$ edición, Madrid, Editorial Trotta, 2003), 156 págs. Revista de estudios histórico-jurídicos, (27), 630-635. Recuperado de https://bit.ly/3cNSmmF

- Ministerio de Justicia y Derechos Humanos (2019). Boletín Estadístico Institucional 2019. Recuperado de https://bit.ly/2zq28fT

- Ortiz, S. (20 de mayo de 2020) Reacción tras proyecto de archivamiento en el Congreso: El Ejecutivo pedirá facultades para deshacinar penales. El Comercio p.A 8.

- Pastor F. (2019) Las gracias presidenciales como política pública para combatir el hacinamiento penitenciario: análisis del Perú 2001-2018 (Tesis para optar el título de licenciada en ciencia política y gobierno) Pontificia Universidad Católica del Perú. Recuperado de https://bit. ly/2TkhtG4

- Poder Ejecutivo (2017) Decreto Legislativo 1325. Decreto Legislativo que declara en emergencia y dicta medidas para la reestructuración del Sistema Nacional Penitenciario y el Instituto Nacional Penitenciario. Recuperado de https://bit.ly/2SW4ABz

- Poder Ejecutivo (2020) Decreto Supremo 013-2018-JUS. Decreto Supremo que prorroga la emergencia dispuesta por el Decreto Legislativo $N^{\circ} 1325$ para la reestructuración del Sistema Nacional Penitenciario y el Instituto Nacional Penitenciario. Recuperado de https:// bit.ly/2Lht6ZX

- Varios autores (2015) Código Procesal Constitucional comentado. Tomo I. Lima, Perú: Gaceta Jurídica.

- Villena, P. (2020) Sobreviviendo con la COVID-19 en las cárceles del Perú. La Ley. Recuperado de https://bit.ly/2T2QTRn

Fecha de recepción: 22 de mayo de 2020

Fecha de aceptación: 01 de junio de 2020 